\title{
Design of a new layout for sublevel caving at depth
}

\author{
C Quinteiro Luossavaara-Kiirunavaara Aktiebolag (LKAB), Sweden
}

\begin{abstract}
$\angle K A B$ has been mining iron ore with the sublevel caving mining method in northern Sweden for more than 60 years. Throughout the years, $L K A B$ has improved this mining method to stay competitive in a tough international iron ore market. Improvements in drilling and blasting technology have helped LKAB increase the scale of sublevel caving and therefore decrease its mining costs in development. Today, sublevels at $L K A B$ are up to $30 \mathrm{~m}$ high.

In recent years, with increasing mining depth $L K A B$ has been experiencing decreased availability of some production areas due to rockfalls induced by seismicity and orepass instabilities. LKAB started a study in 2017 to investigate mining under the current main level both at the Kiruna mine and Malmberget mine.

This paper presents part of the results of this study, which is a novel layout for sublevel caving that is more suitable for mining under high horizontal stress and with higher production capacity than the existing layout. This layout has been internally named 'fork layout', since its basic layout looks like a drawing of a fork. This layout divides the orebody into contiguous production areas. A production area is formed by several crosscuts linked together by a transport drift. It is expected that this new layout will have a significantly higher production capacity than the existing transversal sublevel caving layout, and will be more suitable for mining at depth compared with the existing layout. One of the drawbacks of this new layout is the need for more development work than the traditional layout. To decrease the economic impact of this effect on mining costs, a further increase in the sublevel from about 30 to $50 \mathrm{~m}$ high is suggested. This layout is being considered for approval by the LKAB board to a full-scale test at Kiruna.
\end{abstract}

Keywords: sublevel caving, mine design, caving mechanism, high induced stress

\section{Introduction}

LKAB operates two underground iron ore mines in northern Sweden. One mine is located near the city of Kiruna and the other one near the city of Malmberget. These mines have been producing iron ore from underground workings for more than 60 years. During 2017, Kiruna mine produced about $29 \mathrm{Mt}$ of run-of-mine and Malmberget mine about $14 \mathrm{Mt}$. Sublevel caving is the mining method used at these mines. LKAB has a history of using sublevel caving at its mines, and throughout the years it has introduced significant improvements to keep production costs at desirable levels. It should be mentioned that other mining methods have been tried, but today, sublevel caving is the only one used.

One of the key factors affecting the mining costs in sublevel caving is the amount of development work for production. This cost is very dependent of the sublevel height. As the sublevel height increases, the amount of development work necessary for production decreases. LKAB has been pushing the boundaries for sublevel height and thus decreasing mining costs for many years now. In the 1990s, Kiruna mine increased the sublevel height from 12 to $27 \mathrm{~m}$. This was made possible with the development of the in-the-hole and water driven hammers by LKAB Wassara. Borehole accuracy is essential for successful ring blasting and mucking in sublevel caving, and with Wassara technology, LKAB is able to have sublevels of up to $30 \mathrm{~m}$ high.

The deepest mining level at Kiruna mine today corresponds to about 1,080 m below ground. Malmberget mine is mining at about the same depth. The main haulage level at Kiruna mine is located at Level 1365, and at Malmberget mine at Level 1250. The main haulage level at Kiruna mine is a train level, and at Malmberget mine a truck level. The costs involved with the construction of these main levels of transport amounted to about USD 2,300 M (LKAB 2018). Kiruna mine has been classified as a seismically active mine since 2008. 
Seismic activity around the mining areas has caused falls of ground in some drifts and orepass instabilities resulting in undesirable production disturbances. Malmberget mine has also been affected by seismicity, although to a lesser degree than Kiruna mine. Both mines have installed a large microseismic array of geophones to capture and analyse microseismicity to support mine planning and rock mechanics related actions. Kiruna mine has about 230 installed geophones in its microseismic array. It is expected that as mining becomes deeper, the seismicity around the production areas of the mine will increase due to increased induced mining stresses around the openings.

In 2017, LKAB started a study to investigate mining under the existing main level at both mines. According to production plans, both mines will reach the main level by 2030. At this time, a new production system should be in place to replace the current main level. The study was directed to look at possible mining methods for future production areas and at future transport systems of ore from production areas to the surface. This paper describes only one part of this study regarding one new layout for future production areas using sublevel caving, assuming a similar orebody geometry at depth. A diamond drilling program is underway to gather information about the orebody at depth for both mines.

\section{Current sublevel caving layouts}

The magnetite orebody at Kiruna mine is about $80 \mathrm{~m}$ thick, dips about $60^{\circ}$ to the east, and has a strike about north-south. The host rock is metarhyodacite in the hanging wall and metatrachyandesite in the footwall. Uniaxial compressive strength of the footwall rock varies from 90 to $430 \mathrm{MPa}$. The hanging wall rock is about $180 \mathrm{MPa}$ and the ore is about $130 \mathrm{MPa}$. The assumed in situ principal stresses at Kiruna mine at $1000 \mathrm{~m}$ Level are $33 \mathrm{MPa}$ (horizontal perpendicular to the orebody), $26 \mathrm{MPa}$ (horizontal north-south) and $25 \mathrm{MPa}$ (vertical). Geology for the Malmberget mine is different from the Kiruna mine by having several smaller orebodies spread out in the mining area.

Transverse sublevel caving layout is the normal layout at LKAB, but when the orebody is narrow, longitudinal sublevel layout is used. In this paper, only transverse sublevel caving is discussed, i.e. the production drifts are driven across the orebody from the footwall to the hanging wall. The dimensions of the layout of the transverse sublevel caving vary between different orebodies and mines. The dimensions for a typical layout for the Kiruna mine is about $25 \mathrm{~m}$ between crosscuts (production drifts) and about $29 \mathrm{~m}$ for the sublevel height (floor to floor). The dimensions of the crosscuts are about $7 \mathrm{~m}$ wide and $5 \mathrm{~m}$ high. A longitudinal drift is driven in the footwall to link the different crosscuts with the orepasses.

At Kiruna mine, the mine is divided into production blocks about $400 \mathrm{~m}$ long. Each block has 16 crosscuts, one longitudinal drift and four orepasses. Two orepasses are placed on the right and two orepasses are placed on the left of the access drift to the block. Ramps placed in the footwall provide access drifts to the blocks.

A sketch of a typical layout of a production block for the Kiruna mine layout is shown in Figure 1. In this sketch, only the centre line of the drifts is shown. The discontinuous line represents the orebody, and the continuous line represents the drifts. The footwall drift in the sketch is driven parallel to the orebody direction. The sketch indicates the placement of four orepasses and the access drift. This type of layout has been used for many years at LKAB and has been the standard way to mine with transverse sublevel caving with only minor changes. These drifts are rock-reinforced according to a plan for each block. Dynamic rock support with steel meshes, fibre reinforced shotcrete, dynamic rockbolts, etc. are used where required. 


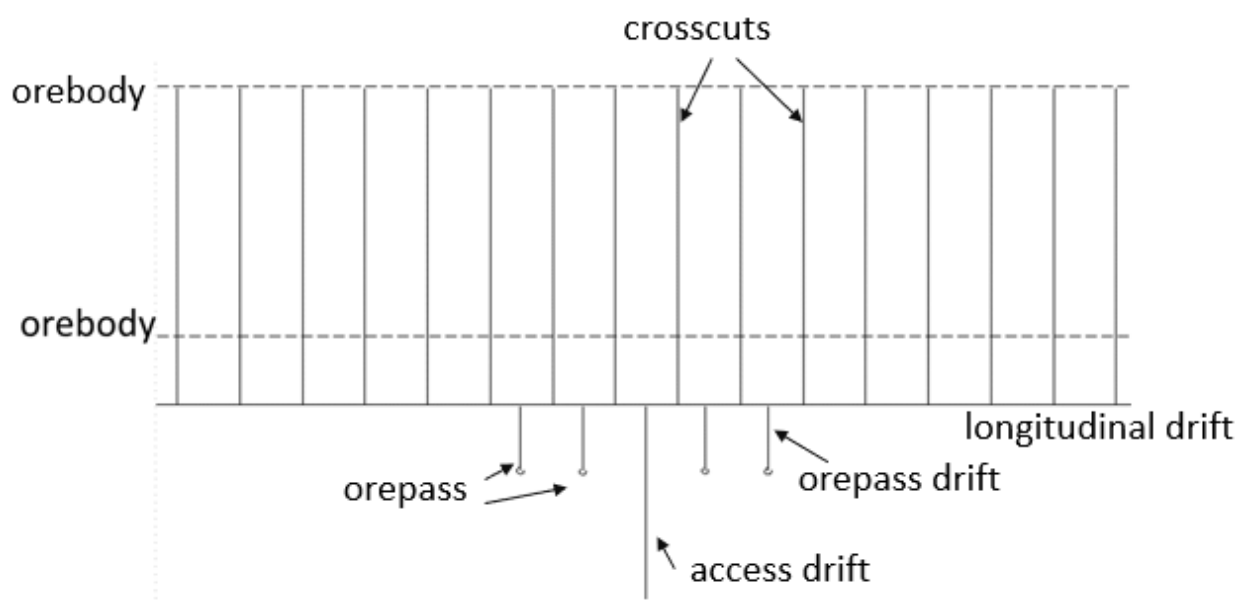

Figure 1 Plan view sketch of a typical block layout for transverse sublevel caving for the Kiruna mine

Kiruna mine has been experiencing rockfalls inside the orepasses and around the footwall drifts in some parts of the mine. The orepasses are raise-drilled with a diameter of $3 \mathrm{~m}$ and each one has a total length of about $300 \mathrm{~m}$ with a dip of about $60^{\circ}$. These rockfalls are typically associated with seismic events located near the affected area. These rockfalls present a hazard to personnel and machinery, causing disturbances in the production capacity of the mine.

Rockfalls in orepasses at Kiruna mine have led to extensive repair work to get them back into production. The repair work consists of filling the orepass with concrete and then raiseboring it again. In 2016 and 2017, a total of $200,000 \mathrm{~m}^{3}$ (LKAB 2018) of concrete was used in repair work of the orepasses. These problems with the instability of the orepasses and footwall drifts is probably related to several factors, including induced mining stresses, local geology, rock properties, applied rock reinforcement, mine design and mining sequence. The information above indicates that there is a need to look further into alternative mine design, mining sequence and reinforcement systems for mining at greater depth at LKAB mines.

This paper focuses on an alternative mine design. One of the possible improvements of the current sublevel caving layout at Kiruna mine, towards mining at greater depths, is the placement of the footwall drifts and orepasses, in relation to the orebody, in a production block. These infrastructures are affected by the changes in mining-induced stresses depending on their relative location in relation to the orebody. Numerical simulation of mining-induced stresses due to sublevel caving for the Kiruna mine shows a steady increase in the differential principal stress, in a given mining level, as one gets closer to the orebody. Historically, LKAB has performed many numerical simulations using finite difference, finite elements and boundary methods used in commercial software.

Figure 2 shows a sketch of the typical behaviour of the differential principal stresses $\left(\sigma_{1}-\sigma_{2}\right)$ in the footwall at depth. A sketch is shown instead of the real simulated values since the important point at this stage is the stress behaviour. The values change depending on selection of geometry, rock mass properties and model behaviour. As mining activity moves downwards, the stresses in the surrounding rock are changed. The changes are greater near the orebody and lesser away from the orebody. This is the expected and interesting behaviour that is shown in Figure 2. As one moves away from the orebody (from point $A$ to point $B$ in the sketch), the differential mining-induced principal stresses decrease. Based on this information, one would expect, assuming all the other parameters remain the same, that by moving the footwall drifts and orepasses away from the orebody one would avoid a high increase in the differential mining-induced stress on these mine infrastructures. This could lead to improved ground stability around these mine openings since, in general, rock failure is associated with high differential stresses. This effect becomes more important as the mine gets deeper. 


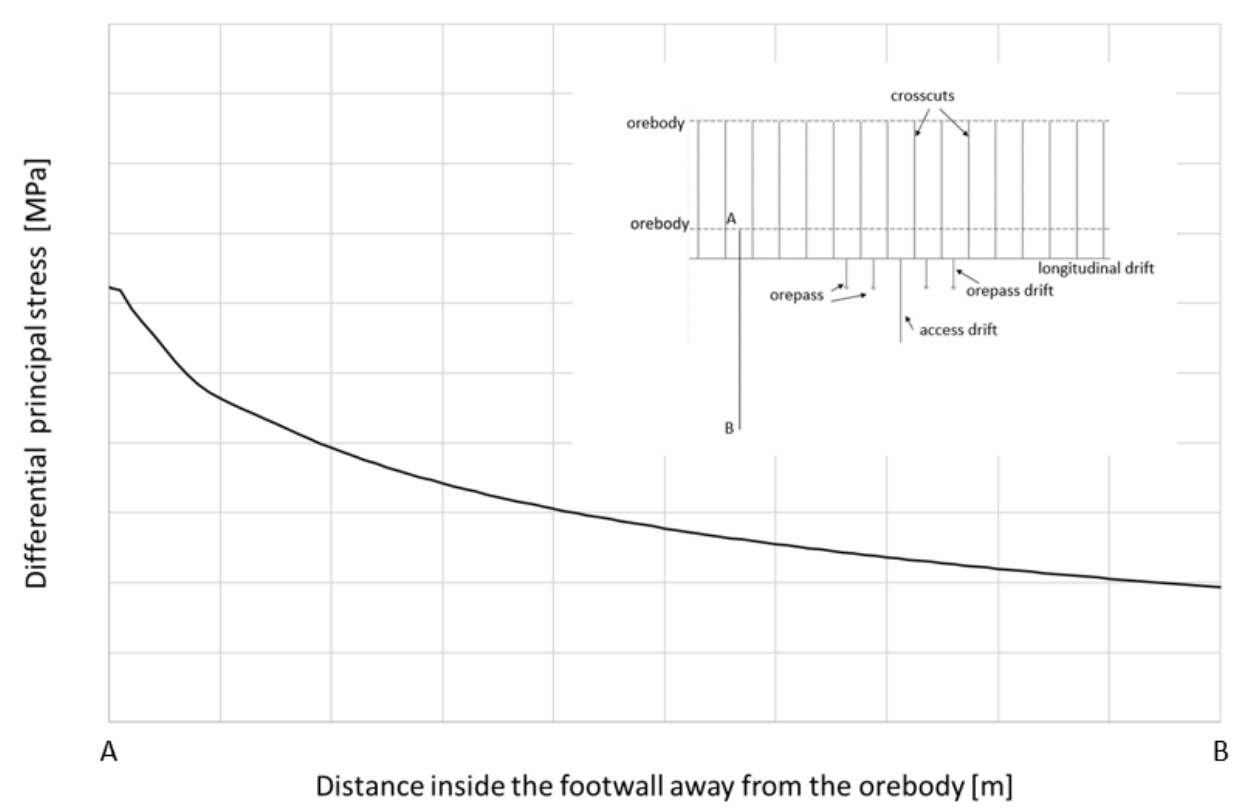

Figure 2 Sketch of the behaviour of the differential principal stress $\left(\sigma_{1}-\sigma_{2}\right)$ in the footwall for sublevel caving at Kiruna mine

\section{$3 \quad$ New sublevel caving layouts for mining at depth}

As discussed previously in this paper, it is expected that the current sublevel caving mining layout used at LKAB underground mines will not work properly at greater depths when mining under the current main level. If sublevel caving is the mining method to be used in the future, it needs to be redesigned to be able to better cope with the expected higher stresses at depth.

It seems that the correct strategy is to move the footwall drifts and orepasses away from the current design locations and place them farther inside the footwall. However, if one would apply this strategy to the current sublevel caving layout, it would result in a large increase in required development and thus a large increase in mining costs. Of course, the farther the location of the footwall drift in the footwall, the larger the cost increase will be, and fewer problems with rock instabilities will be expected. The optimal placement of the footwall drift will be studied later by considering these factors.

Another consequence of moving the footwall drifts and orepasses farther into the footwall is the increase of the tramming distance of the load-haul-dump units (LHD). As this distance becomes larger, the productivity of these machines will get lower, impacting on production capacity and mining costs. At a certain distance, the use of these machines alone will be inadequate, due to a low production capacity and high operating costs. It should be mentioned that the use of LHDs as a production unit at LKAB mines is well established and a proven concept. Until better equipment is available in the market, there is a desire to keep this machine as a production unit.

Figure 3 shows a sketch of the plan view of the current layout with the footwall drift and orepasses moved farther inside the footwall. Observe in the sketch the amount of extra driving required and the increased transport distance for the LHDs from the production drifts to orepasses placed farther inside the footwall from the longitudinal drift. From this discussion, it is easy to see that it is not justified to pursue such a simple change at the current layout (high costs and low production capacity). 


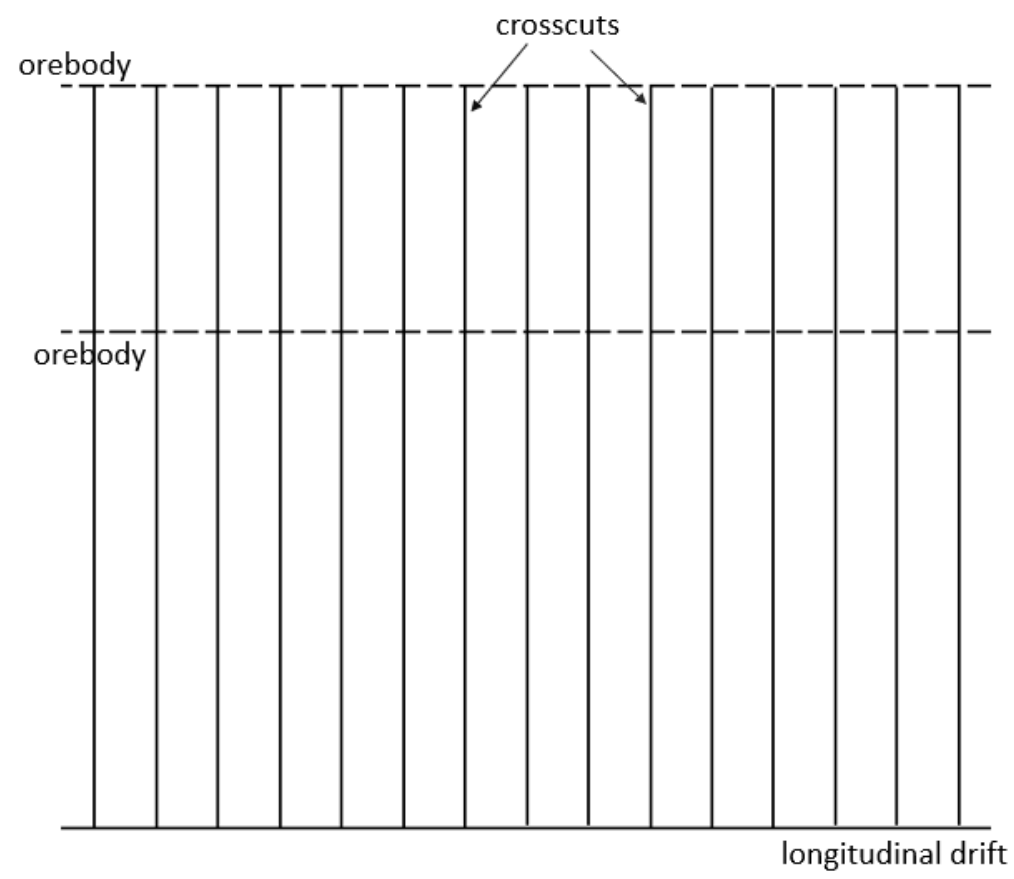

Figure 3 Plan view sketch of a standard layout for transverse sublevel caving with the footwall drift moved inside the footwall

An alternative way to change the current layout is presented in Figure 4, attempting to minimise the amount of development and finding a solution for the increased tramming distance for the LHDs while keeping this equipment as the primary production unit in the area.

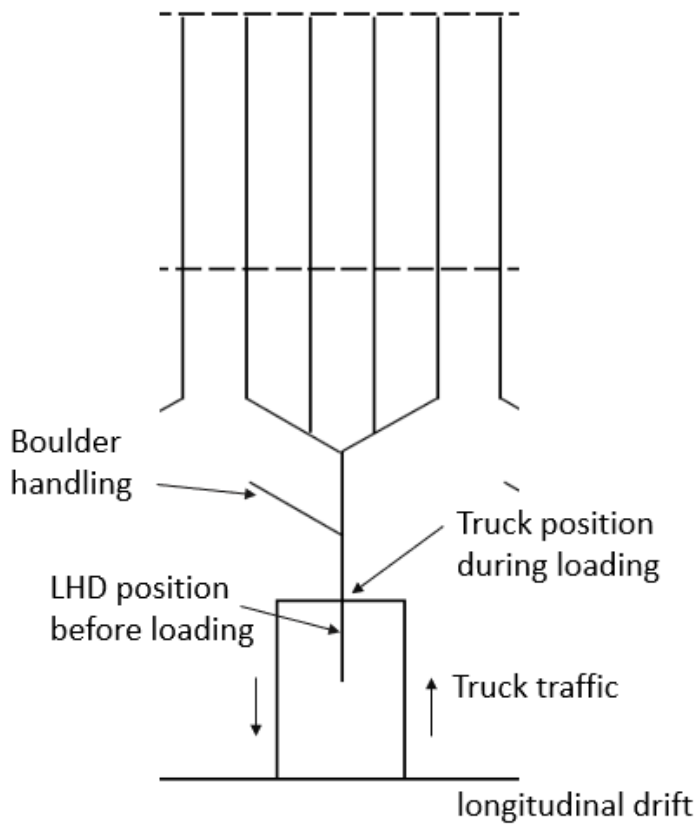

Figure 4 Plan view sketch of a fork layout for transverse sublevel caving with the footwall drift moved inside the footwall 
Figure 4 shows a sketch of a plan view of a new layout for sublevel caving for mining at depth at LKAB underground mines. As in Figure 3, only centre lines are shown in this sketch. Note in this layout that both the footwall drift and the orepasses have been moved farther inside the footwall to minimise possible rockfalls due to changes in mining-induced stresses. The orepasses are not shown in the sketch, but they are placed farther inside the footwall (Figure 1). This layout has been denominated 'fork layout' since its basic drawing unit looks like a fork. The idea of this layout was to keep the advantages of the current layout, to improve its disadvantages while minimising development work. The crosscuts of the current transverse layout have performed well regarding rock stability at LKAB mines, and therefore one should not change its direction in the new layout. Significant parameters of the layout, such as dimensions of the drifts and rock reinforcement, will be studied later to find the optimal design. These crosscuts are driven in the same direction as the principal stress and have experienced only minor rock stability problems in the past. The distance between crosscuts is kept the same as the current layout at $25 \mathrm{~m}$, but this is a parameter that is yet to be decided. Drift dimensions at depth are also parameters to be investigated later. The drift linking the crosscuts inside a fork is placed a bit farther inside the footwall and expected to have better stability. This area of the layout will be investigated later to assure long-term rock stability. Another improvement in this proposed layout is the increase in the production capacity of the orebody which is discussed below.

The fork layout shown in Figure 4 has four crosscuts linked together into one production area. This production area is thus $100 \mathrm{~m}$ long. The ideal number of linked crosscuts per production area could vary between four to eight depending on orebody geometry, production requirements and costs. This fork layout is designed to have an LHD and trucks as a production unit working together. One LHD operates in the production area shown in Figure 4. The plan is that both LHDs and trucks would be autonomously operated and battery/electricity-driven.

In the sketch of the fork layout shown in Figure 4, one can observe a place for the LHD to store boulders when needed, for further size reduction before loading in the truck. The point of loading the truck is a four-way intersection that is properly rock reinforced and designed to allow automation and productivity. Note that this is only a conceptual sketch showing ideas, and care has not been taken to round off the corners for optimal conditions. The idea is that the LHD would return with a full bucket towards the four-way intersection for loading the truck. Once the truck is loaded, it will transport the ore to an orepass at a certain distance away inside the footwall. This could be in the same level as mucking or even to an orepass or crusher station placed in another level. This option will require transport using ramps. A truck capacity of about one to three LHD buckets could be used in this layout, depending on geometry and cycle time. The strategy is to keep the LHD filling the trucks with minimal waiting time for the trucks. Naturally, the tramming distance of the LHDs influences the production rate capacity, and therefore it is a parameter to be investigated further. Also, the optimal placement of the footwall drifts will be investigated considering rock mechanics issues, production capacity and mining costs.

Figure 5 shows a sketch of a possible production block using the fork layout. In this case, four fork layouts can be grouped together as a production block by the footwall drift. This production block is $400 \mathrm{~m}$ long and has four possible production areas. This is an increase from two to four when compared with the current layout, therefore giving it a higher production capacity per block. This is a very important feature of this new layout, enabling it to have a high production capacity even from shorter footprint orebodies. Such a production block could have between two and four orepasses to transport the ore to a level of transport if this option is selected. Ventilation of a production block must be done in a different manner than today and it is not seen as a problem.

The optimal number of forks per production block and the number of crosscuts per fork layout are also parameters that will be studied later. In general, in this new layout, the necessary development work will decrease with an increased amount of production crosscuts per fork, but the production capacity of the orebody per level will decrease. 
As mentioned previously, one disadvantage of the fork layout is the increase in the amount of development required for production when compared with the current layout. An increase of up to $100 \%$ in the amount of development is estimated when compared with the current layout and the same orebody geometry. Therefore, to keep the costs of the sublevel caving at a certain level, it is necessary to increase the sublevel height when using the fork layout. The idea is that the savings with the increase in sublevel height should cover most of the costs involved with more development with the fork layout. Other factors associated with the fork layout, such as increased productivity, could bring the total mining costs to a desirable level. Therefore, increasing the sublevel height is essential to the applicability of the fork layout at LKAB. This is discussed below.

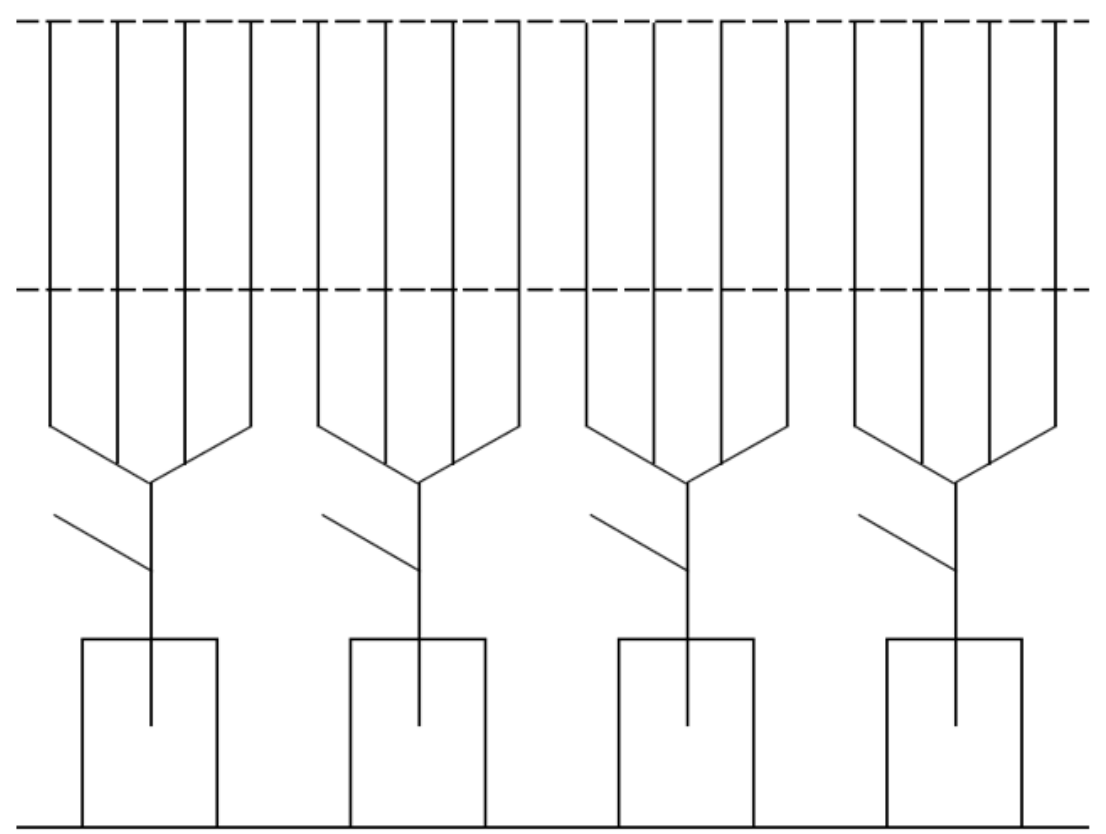

Figure 5 Plan view sketch of a block layout for transverse sublevel caving with four forks

\section{$4 \quad$ Testing sublevel caving with $50 \mathrm{~m}$ height at LKAB}

LKAB has been using a sublevel height of about $27 \mathrm{~m}$ at Kiruna mine since about the mid-1990s. This height has not changed significantly since then and today the maximum sublevel height is $30 \mathrm{~m}$ at Malmberget mine. As discussed earlier, there is a need to increase the sublevel height when using the fork layout at depth to avoid a high increase in the amount of development work and thus a large increase in mining costs. An important parameter for increasing the sublevel height is the ability to drill and charge long blastholes according to a plan. Increasing the sublevel height leads to an increase in the borehole length of the rings. Therefore, a challenge is to keep deviations to a minimum at the bottom of the drillhole. LKAB Wassara is investing in new technology to be able to accomplish this feature by 2020.

LKAB is targeting a sublevel height of $50 \mathrm{~m}$ in the future to keep mining costs at a reasonable level using the fork layout. This increase may seem extreme and many people could be sceptical about it. It is much easier to see difficulties than solutions, even when discussing increased sublevel height. However, there is a possibility to carry out sublevel caving at depth with safety and good economics at LKAB by using the fork layout with increased sublevel height. Moreover, it is feasible to try this increase even today with existing machinery and with a very good chance of success. In fact, it is more difficult to justify the opposite - why we should not try an increased sublevel height. After more than 20 years, it is time again for LKAB to try to push the boundaries of sublevel caving.

Ideally, it would be better to increase sublevel height in smaller steps, but this would take many years and require large resources to field test, monitor and draw conclusions. Also, it is desirable to test larger sublevel heights at greater depths than today, since that is the knowledge required, but this would also require much 
time and resources. Unfortunately, there is not enough time and resources available and, therefore, it is necessary to use engineering knowledge and judgement to reach a reasonable compromise. By the end of 2022, it is expected that a new design on how mining is to be done at greater depths at LKAB mines will be devised. Thus, to achieve that and not to compromise, the most important goal would be to field test the performance of sublevel caving with $50 \mathrm{~m}$ sublevels as soon as possible. A search for a possible test site has begun.

One constraint to a possible test site is that current mine production plans should not be affected. We were lucky enough to find and to have the possibility to use a smaller orebody south of the Kiruna mine to carry out these tests without disturbing current production plans and with the possibility to have the results within the available timeframe. This orebody has a dip of about $75^{\circ}$ to the east, which is steeper than the main orebody. Its thickness varies from 20 to $50 \mathrm{~m}$ and, therefore, it is thinner than the main orebody. Ideally, we would like to have a much thicker orebody for the tests, but again, we had to compromise. This orebody is known by the name Konsuln. Mining at this orebody is being done today with sublevel caving at around Level 400, which is about $700 \mathrm{~m}$ shallower than the deepest mining horizon at the main orebody at Kiruna mine. This difference in mining depth was therefore a compromise that had to be accepted. The effects of the mining depth will have to be assessed later and the focus of this test would be to see if we can successfully mine with sublevel caving using $50 \mathrm{~m}$ sublevel intervals and assess the production performance of the fork layout. Care is taken, however, to give the best available conditions today for this test to succeed (drilling, charging and blasting).

It is planned to mine three sublevels in Konsuln to gather sufficient information to judge the performance of this new layout with higher sublevels and production performance of the fork layout. The first level will have a $40 \mathrm{~m}$ sublevel height and the second and third levels will be $50 \mathrm{~m}$ high. Two crosscut spacings will be tested in this area $(25$ and $22 \mathrm{~m}$ ). The size of the crosscuts is kept the same as in the Kiruna mine $(7 \mathrm{~m}$ wide $\times 5 \mathrm{~m}$ high). The sublevel rings will be designed in the first levels according to current drilling capacity of the mine. The maximum length of drilled boreholes is set to $60 \mathrm{~m}$. However, we expect to use new drilling technology when designing the rings of the last sublevel. A total of about 50 crosscuts will be mined and monitored in these three levels.

Development work is planned to start in 2018 and the entire test is scheduled to be finished by 2023, after mining about $9 \mathrm{Mt}$ of iron ore. It is expected that this test will provide us with enough representative data to assess the new layout for mining at depth with sublevel caving at LKAB mines. A monitoring program using smart markers is planned to be installed in this area to gain insight into the gravity flow performance of this layout. It is expected that we will be able to assess primary, secondary and tertiary ore recovery of blasted rings as well as information on draw width. LHDs equipped with bucket scales will be used to monitor dilution during mucking. Boulders requiring size reduction will also be monitored.

Figure 6 shows a plan view of the proposed layout of the test area for Level 536. This layout is also a compromise between the conditions of the site, production requirements and test requirements. One can observe a modified fork layout on the right and left hand side of the test site. The design of the loading point for LHDs into trucks allows even electric LHDs using cables. In this area, it is also planned to test autonomous LHDs and autonomous trucks as production units. Battery-operated LHDs and trucks will also be tested in this area. A network allowing wireless communication capacity for flow of information is also planned to be tested in here. Other tests are also planned for this area to support future mining at depth at LKAB. 


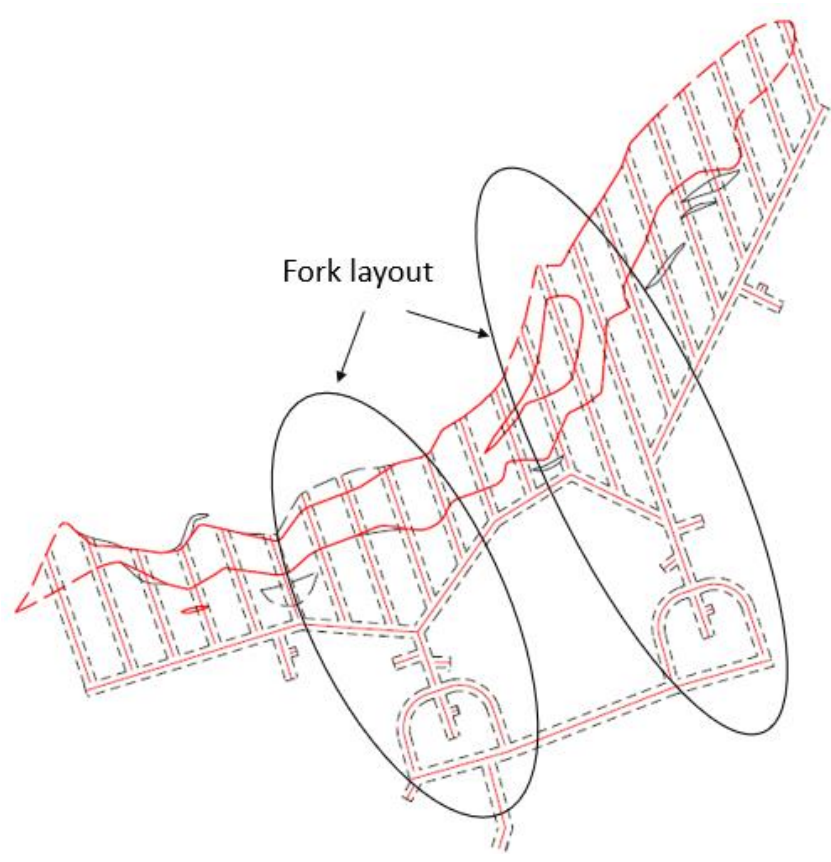

Figure 6 Plan view of the proposed layout of Level 536 for transverse sublevel caving with fork layout and $50 \mathrm{~m}$ sublevel height

\section{Conclusion}

This paper has described a new mining layout for sublevel caving at depth for LKAB. This layout could help LKAB to continue mining its mineral resources that exist under its current main levels with higher productivity and be better suited for expected higher mining-induced stresses. According to current production plans, a new mining system should be in place around 2030 for both underground mines at LKAB. This new layout, denominated 'fork layout', would require an increase in the sublevel height currently used at LKAB from about 30 to $50 \mathrm{~m}$. A full-scale test area has been designed to assess the applicability of such layout. A total of three sublevels and about $9 \mathrm{M}$ t of ore will be mined, monitored and evaluated to assess its applicability at LKAB. Critical development work started in 2018 , so as not to delay the test, but a decision by the LKAB Board on this subject is expected to be taken in 2018. In parallel to the full-scale test, a series of investigations will be carried out in the next five years to support the optimal design of the future mining system at LKAB underground mines.

\section{Acknowledgement}

The author thanks LKAB for allowing the publication of this paper and all the colleagues at LKAB for their encouragement and support of this work.

\section{References}

LKAB 2018, Annual and Sustainability Report 2017, LKAB, Luleå, pp. 25-28. 
